Cite this: RSC Adv., 2019, 9, 31202

Received 3rd September 2019

DOI: $10.1039 / c 9 r a 07052 d$

rsc.li/rsc-advances
Check for updates Accepted 18th September 2019

\section{A tough and sustainable fiber-forming material from lignin and waste poly(ethylene terephthalate) $\uparrow$}

\author{
Kokouvi M. Akato, ${ }^{\text {ab }}$ Ngoc A. Nguyen, (D) Kalavathy Rajan, (D) a David P. Harper ${ }^{a}$ \\ and Amit K. Naskar iD *abc
}

In this report we describe repurposing of recycled polyesters as a matrix for lignin-a biorefinery coproduct that is used as a solid fuel and needs to find higher value-to make sustainable high-performance thermoplastic materials. Brittle lignin oligomers, isolated from plant biomass, require a low-melting host polymer matrix to form a rigid and tough renewable material. We demonstrate controlled lignin dispersion and interfacial interactions in softened recycled polyethylene terephthalate (PET) using a simple solvent-free, melt-blending technique. To avoid lignin degradation and devolatilization during melt processing, it was thermally treated. Tall oil fatty acid was used to enable PET processability at low enough temperature to accommodate lignin without charring. Chemical analysis reveals reduction of aliphatic hydroxyl content from $2 \mathrm{mmol} \mathrm{g}^{-1}$ to $1.63 \mathrm{mmol} \mathrm{g}^{-1}$ and an increase of total phenolic hydroxyl moieties from 5.86 to $6.64 \mathrm{mmol} \mathrm{g}^{-1}$ and cleavage of $\beta-O-4$ ether linkages due to thermal treatment. Structural transformation of lignin macromolecules during heat treatment was further confirmed by an increase in molar mass and improved thermal stability. Interfacial interactions between lignin and PET were assessed from mechanical properties and thermal analyses. Thermal treatment not only helps to improve the stability of lignin but also slightly reduces the size of the dispersed lignin domains via favored interfacial interactions with the PET matrix. These methods improve mechanical properties of the material. Further, incorporation of lignin in the plasticized PET matrix increases the ductility in the blended products. The method we discuss here utilizes industrial wastes and co-products, and it does not require solvent or toxic chemicals during the reactive extrusion process that yields complete conversion to products.

\section{Introduction}

Conservation of petrochemicals and utilization of wastes and renewable materials are essential to avoid industrial pollution. ${ }^{1}$ Proposed reliable solutions include usage of materials made

${ }^{a}$ Center for Renewable Carbon, University of Tennessee, Knoxville, Tennessee 37996, USA. E-mail: naskarak@ornl.gov

${ }^{b}$ Bredesen Center for Interdisciplinary Research and Graduate Education, University of Tennessee, Knoxville, Tennessee 37996, USA

${ }^{c}$ Carbon and Composites Group, Chemical Sciences Division, Oak Ridge National Laboratory, Oak Ridge, Tennessee 37831, USA

$\dagger$ This manuscript has been authored by UT-Battelle, LLC, under contract DE-AC05-00OR22725 with the US Department of Energy (DOE). The US government retains and the publisher, by accepting the article for publication, acknowledges that the US government retains a nonexclusive, paid-up, irrevocable, worldwide license to publish or reproduce the published form of this manuscript, or allow others to do so, for US government purposes. DOE will provide public access to these results of federally sponsored research in accordance with the DOE Public Access Plan (http://energy.gov/downloads/doe-public-access-plan).

\$ Electronic supplementary information (ESI) available. See DOI: 10.1039/c9ra07052d from renewable sources and development of value-added products from wastes. ${ }^{2}$ Lignin, a natural polymer in biomass, is a coproduct from paper mills and biorefineries and is a promising feedstock for renewable plastics. Both lignin utilization and recycling of waste plastic remain immature, and the technological deficiency is primarily caused by the excessive emphasis on direct use of these materials as fillers and the approach results in downgraded products. In this context we propose combination of post-consumer polyethylene terephthalate (PET) waste and lignin-currently considered as a cheap source of energy via combustion-to produce a new class of sustainable polymeric materials. This creates a favorable solution via value-addition to both renewable wastes, spent and recycled materials, and curtailing environmental concerns. However, reused PET products are very brittle, and they become further brittle when melt-mixed with lignin at the melting temperature of PET. Lignin degrades and forms char at the melting temperature of PET.

PET is a semi-crystalline thermoplastic polyester broadly used in packaging industries. Wastes generated during manufacturing and consumption of PET are detrimental to the 
environment because PET lacks biodegradability. ${ }^{3}$ Thus, recycling these wastes is desired for environmental protection, conservation of petrochemicals and energy, and to generate additional revenue streams. Currently, recycled waste PET is used in construction, packaging, and composite applications. For example, recycled PET is used readily in structural concrete reinforcement, where crack control and enhancement of ductility are valuable. ${ }^{4,5}$ Waste PET is also used to develop new materials through blending with other polymers. ${ }^{6-9}$ Most blends are immiscible at molecular levels due to unfavorable interfacial tension between the components and often require the addition of a compatibilizer.

Blends of PET and lignin were evaluated as an alternate route in the efforts of lignin valorization to derive thermoplastic/ lignin alloys. ${ }^{10-16}$ Unfortunately, only moderate interactions between thermally degraded lignin and the PET matrix and a downward trend of the tensile strength as a function of the amount of lignin loading were observed. For example, a blend of PET and $30 \mathrm{wt} \%$ lignin-prepared in our laboratory at $260{ }^{\circ} \mathrm{C}$ shows that the blend only retains less than $38 \%$ of tensile stress of waste PET and a significant decrease in elongation. Therefore, in most cases, lignin was modified to introduce functional moieties that favor strong interactions between the components. Adequately tailored interfacial interactions, either by chemical route or by addition of compatibilizer, drastically improve the dispersion of fine homogenous lignin domains that is valuable for performance enhancement of the blends. In that regard, esterification is often used as a lignin modification route. ${ }^{17,18}$ The additional step increases cost and creates a need for chemical disposal, which constitutes an inherent disadvantage for the new polyester-lignin blends for industrial adoption.

Most of the earlier reports on PET-lignin blends claim partial miscibility or total immiscibility between lignin and the host matrix with widespread variations in structures and properties based on microscopy, differential scanning calorimetry (DSC), and Fourier transformed infrared (FTIR) spectroscopy. Yet very little information is available on process engineering of the blends. Due to the high melting temperature $\left(\sim 260^{\circ} \mathrm{C}\right)$ of PET, choosing appropriate blending temperatures for PET/lignin blends is important to avoid lignin degradation during mechanical blending. Jeong et al. ${ }^{14}$ reported mixing temperature of $170{ }^{\circ} \mathrm{C}$ for blends of lignin and synthetic polymers including PET, which yielded heterogeneous blends of PET. Temperature setup as high as $265^{\circ} \mathrm{C}$ were used elsewhere. ${ }^{10} \mathrm{In}$ general, the rheology of the blend components impacts processing and phase behavior of the resulting PET/lignin blends.

The scope of this study lies within usage of melt-based blending techniques to develop partially renewable polymer blends of post-manufacturing PET waste and an organosolv lignin, a low-cost natural polymer obtained from biomass processing industries without chemical modification. In general, normal processing temperatures $\left(265{ }^{\circ} \mathrm{C}\right.$ to $\left.280{ }^{\circ} \mathrm{C}\right)$ of postmanufacturing PET are deemed detrimental for nanoscale dispersion of lignin without thermal degradation of the lignin phase. For this reason, lignin can be thermally treated to remove low molecular weight volatile materials and improve its heat resistance during blending. It also helps to avoid devolatilization that negatively impacts the blend morphology (by creating porosity) and properties. Based on our previous report, ${ }^{19}$ a renewable plasticizer-tall oil fatty acid (TOFA) that is essentially oleic acid enriched oil-at $10 \mathrm{wt} \%$ relative to PET was added to help soften PET chains and to reduce its meltprocessing temperatures by $20^{\circ} \mathrm{C}$. TOFA is another co-product (apart from lignin) of the paper industry, and plant-derivatives used here in combination with the recycled PET results in lignin-based thermoplastic alloys that are malleable and reprocessable. The process does not need any solvent or toxic chemicals to make products. The process via melt-phase extrusion does not generate significant wastes. Thus, it fulfills basic principles of green chemistry. Combining thermal treatment with plasticizing permits appropriate choices in mixing temperature, to control dispersion of lignin, and associated promotion of interfacial interaction that are necessary to create higher performance sustainable composites of lignin. In summary, this study involves adept characterization of lignin, its structural transformation during thermal treatment followed by an assessment of interfacial interactions of lignin in PET matrix, and subsequent correlation to morphology and mechanical properties of sustainable PET/lignin blends.

\section{Experimental section}

\section{Materials}

Thermoplastic polyester PET was received from Eastman Chemical USA. It is scrap from the resin manufacturing facility and supplied as white ground plastic. Melt flow rate (MFR) measured in our laboratory is $55 \mathrm{~g} / 10 \mathrm{~min}$ at $280^{\circ} \mathrm{C}$ at $2.16 \mathrm{~kg}$ applied force. The PET was dried under vacuum at $130^{\circ} \mathrm{C}$ for 12 hours to avoid hydrolytic degradation during melt processing. Organosolv hardwood lignin (L) was provided by Lignol Innovations, Canada. The lignin melts fully at $147^{\circ} \mathrm{C}$ and flows at $163{ }^{\circ} \mathrm{C}$ (Fisher Scientific melting point tester). The lignin was dried at $60{ }^{\circ} \mathrm{C}$ for 8 hours. The tall oil fatty acid (TOFA) was acquired from Westvaco Chemicals, Charleston SC. It is a Westvaco L-5 Tall oil fatty acid that primarily consists of oleic acid. The specifications of the TOFA were reported as: acid number (min 190), rosin acids (max 5\%) and color or Gardner $(\max 7)$.

\section{Lignin thermal treatment and characterization}

The lignin (L) was thermally treated in a vacuum oven at $200{ }^{\circ} \mathrm{C}$ for 60 minutes to improve its thermal stability. The thermally treated lignin is identified as $\mathrm{L}_{\mathrm{HT}}$. Both as-received $\mathrm{L}$ and $\mathrm{L}_{\mathrm{HT}}$, were characterized using Gel permeation chromatography (GPC) to evaluate molecular weight and molecular weight distribution (see ESI:). Functional features were characterized and quantified by ${ }^{31} \mathrm{P}$ NMR and $2 \mathrm{D}{ }^{1} \mathrm{H}^{13}{ }^{13} \mathrm{C}$ HSQC NMR spectroscopy using preparation and analysis methods previously reported. ${ }^{20-22}$ Thermogravimetric analysis was used to study thermal stability of the lignin in a nitrogen atmosphere from $100{ }^{\circ} \mathrm{C}$ to $800^{\circ} \mathrm{C}$ at $10^{\circ} \mathrm{C} \mathrm{min}{ }^{-1}$ after a drying step at $100{ }^{\circ} \mathrm{C}$ for $20 \mathrm{~min}$. 


\section{Blend preparation and characterization}

Blends of recycled PET and lignin at 10, 20 and $30 \mathrm{wt} \%$ lignin loading of both as-received lignin (L) and thermally treated lignin $\left(\mathrm{L}_{\mathrm{HT}}\right)$ were prepared respectively, with $10 \mathrm{wt} \%$ of renewable plasticizer relative to the PET weight at $240{ }^{\circ} \mathrm{C}$. The plasticized PET is symbolised as $\mathrm{PET}_{\mathrm{PL}}$. A Haake MiniLab corotating twin-screw extruder (Thermo Scientific) with screw length of $110 \mathrm{~mm}$ was used at screw rotation speed of $30 \mathrm{rpm}$. In a different setup, the extruder was fitted with a die to generate a monofilament of 0.20 to $0.40 \mathrm{~mm}$ diameter. The partially renewable blends are identified as $\mathrm{PET}_{\mathrm{PL}} / 10 \mathrm{~L}$, where $10 \mathrm{wt} \% \mathrm{~L}$ was added and $\mathrm{PET}_{\mathrm{PL}} / 30 \mathrm{~L}_{\mathrm{HT}}$, where $30 \mathrm{wt} \% \mathrm{~L}_{\mathrm{HT}}$ were added respectively. All neat PET filaments used in this study were generated at $280{ }^{\circ} \mathrm{C}$ and used as reference. A differential scanning calorimeter (DSC Q2000, TA Instruments) was used to determine the thermal transitions of the control PET and its lignin-derived blends. Samples with mass of approximatively 3$4 \mathrm{mg}$ each were loaded in hermetic pans for measurements. A cycle of heating-cooling-heating from $-50{ }^{\circ} \mathrm{C}$ to $230{ }^{\circ} \mathrm{C}$ at $10{ }^{\circ} \mathrm{C} \mathrm{min}^{-1}$ and an isothermal of $2 \mathrm{~min}$ after first heating were used. Thermal decomposition of the blends was evaluated using thermogravimetric analyzer (TGA Q500, TA Instruments) under oxidative atmosphere from $100{ }^{\circ} \mathrm{C}$ to $600{ }^{\circ} \mathrm{C}$ at $20{ }^{\circ} \mathrm{C} \min ^{-1}$ after a short drying step. A Zeiss EVO MA 15 scanning electron microscope was used to obtain micrographs of the cryo-fractured surfaces of the blends. The samples were kept in $1 \mathrm{M} \mathrm{NaOH}$ solution for $20 \mathrm{~min}$ at $80^{\circ} \mathrm{C}$ after cryofracture before SEM analysis to remove lignin phases from the surface. Washed and dried samples were coated with gold to avoid charging when images were collected. Images were collected at an operating voltage of $20 \mathrm{kV}$.

Monofilaments of control PET and its lignin-derived blends were tested using an Instron 5943 equipped with Bluehill 3 software and pneumatic side action grip. The crosshead speed

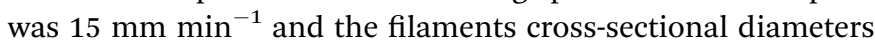
were used for calculation of cross-sectional area and applied stress. Dynamic mechanical analysis (DMA) measurements were carried out on the monofilaments (diameter $0.20-0.40 \mathrm{~mm}$ depending on the sample) at $0.1 \%$ strain rate, discrete frequencies of 1,10 , and $100 \mathrm{~Hz}$, and between $30^{\circ} \mathrm{C}$ and $150{ }^{\circ} \mathrm{C}$ scanned at $3{ }^{\circ} \mathrm{C} \mathrm{min}^{-1}$. The rheological properties were analyzed using the Discovery Hybrid rheometer (DHR-3, TA instruments). All measurements were carried out in the linear regions at $3 \%$ strain in nitrogen atmosphere. Frequency sweeps from 100 to $1 \mathrm{rad} \mathrm{s}^{-1}$ at $240{ }^{\circ} \mathrm{C}$ and $250{ }^{\circ} \mathrm{C}$ were performed.

\section{Results and discussion}

\section{Lignin structural transformation}

Lignin has gained valuable importance recently in preparation of a new class of renewable thermoplastic elastomeric materials. $^{23,24}$ Lignin is an excellent renewable feedstock for manufacturing of environment-friendly materials because of its multifunctional nature and associated chemistries. Here, lignin was thermally treated at $200{ }^{\circ} \mathrm{C}$ under vacuum for 60 minutes to avoid thermal decomposition during blending with recycled
PET. Detailed insight into the microstructural transformation induced by thermal treatment is important for the final properties of the manufactured blends. ${ }^{31} \mathrm{P}$ NMR and 2D HSQC NMR were used to identify and quantify the chemical group profiles of both the as-received and thermally treated lignins.

Phosphitylation of $\mathrm{OH}$ groups in lignin allow quantification of different $\mathrm{OH}$ moieties of lignin by ${ }^{31} \mathrm{P}$ NMR analysis. The ${ }^{31} \mathrm{P}$ NMR spectra with chemical shifts and microstructural assignments are shown in Fig. 1, whereas the amount of $\mathrm{OH}$ groups determined from the spectra is summarized in Table 1 . Thermal treatment decreased the aliphatic $\mathrm{OH}$ content of lignin. L has the higher amount of aliphatic hydroxyl $\left(2.01 \mathrm{mmol} \mathrm{g}^{-1}\right)$ compared to $\mathrm{L}_{\mathrm{HT}}\left(1.63 \mathrm{mmol} \mathrm{g}^{-1}\right)$. This indicates that during thermal treatment, structural transformation of lignin starts with dehydration which eliminates the side chain $\mathrm{OH}$ groups. ${ }^{25}$ The total amount of phenolic $\mathrm{OH}$ increased after thermal treatment, however, the carboxylic group content remained the same. $\mathrm{L}$ is an organosolv-extracted hardwood lignin and is expected to have phenolic syringyl (S) and guaiacyl (G) hydroxyl groups, with little to no $p$-hydroxyphenyl $(\mathrm{H}) \mathrm{OH}$ groups. ${ }^{\mathbf{2 0 2 6}}$ The results are in accordance as these two groups are higher than the $\mathrm{H}-\mathrm{OH}$ groups. Moreover, thermal treatment led to an overall increase of phenolic $\mathrm{OH}$ groups in $\mathrm{L}_{\mathrm{HT}}$ possibly due to the cleavage of $\beta-\mathrm{O}-4$ linkages; specifically, increase in $\mathrm{H}-\mathrm{OH}$ groups signifies additional demethoxylation of $\mathrm{S}$ and $\mathrm{G}$-lignin at the 3,5- and 3-positions, respectively. ${ }^{27}$

Two regions of the 2D HSQC NMR spectra analyzed are shown in Fig. 2. Cross peak assignments and corresponding inter-unit linkages are available in Fig. S1 and Table S1 (ESI The regions possess similarities between the two treatments ( $\mathrm{L}$ or $\mathrm{L}_{\mathrm{HT}}$ ) except for a few signals. The cross peaks corresponding to $\mathrm{C}_{\alpha}-\mathrm{H}_{\alpha}$ in $\beta-\mathrm{O}-4^{\prime}$ substructures $\left(\delta_{\mathrm{C}} / \delta_{\mathrm{H}}=71.9 / 4.9\right)$ and $\mathrm{C}_{\beta}-\mathrm{H}_{\beta}$ in $\beta-\mathrm{O}-4$ substructures linked to syringyl units $\left(\delta_{\mathrm{C}} / \delta_{\mathrm{H}}=86.3 / 4.15\right)$ were significantly reduced or disappeared after thermal treatment. The $\mathrm{C}_{5}-\mathrm{H}_{5}$ and $\mathrm{C}_{6}-\mathrm{H}_{6}$ in guaiacyl units were also reduced. This indicates that $\beta-\mathrm{O}-4^{\prime}$ and $\beta-\mathrm{O}-4$ aryl ether bonds cleaved during thermal treatment and confirms the ${ }^{31} \mathrm{P}$ NMR results discussed above. The $\beta-\mathrm{O}-4$ linkages are easily altered by heat as discussed in previous reports. ${ }^{27}$ The expectation is that ether radicals and phenoxyl radicals will result from these cleavages and react among themselves to initiate crosslinking reactions (condensation) or remain available for further interactions (physical) during melt blending of lignin with the engineered polyester. Moreover, hindered phenolic $\mathrm{OH}$ groups in lignin are free radical scavengers that too are susceptible to these radicals for further condensation reactions. The possibility of condensation reactions occurring among the lignin free radicals generated during thermal treatment explains the increase of 5substituted groups $(\mathrm{S}-\mathrm{OH})$, and condensed $\mathrm{G}-\mathrm{OH}$ in $\mathrm{L}_{\mathrm{HT}}$ (Table 1).

Molecular mass and its distribution for both lignins obtained by GPC indicate significant influence of thermal treatment at $200{ }^{\circ} \mathrm{C}$ on structural transformation of lignin. GPC results show increases in $M_{\mathrm{n}}, M_{\mathrm{w}}$ and $M_{\mathrm{w}} / M_{\mathrm{n}}$ after thermal treatment. L was found to have $M_{\mathrm{n}}=890, M_{\mathrm{w}}=1486$, and $M_{\mathrm{w}} /$ $M_{\mathrm{n}}=1.67$, while $\mathrm{L}_{\mathrm{HT}}$ had $M_{\mathrm{n}}=1103, M_{\mathrm{w}}=1924$, and $M_{\mathrm{w}} / M_{\mathrm{n}}=$ 1.75. The increasd average molecular weight is the result of 


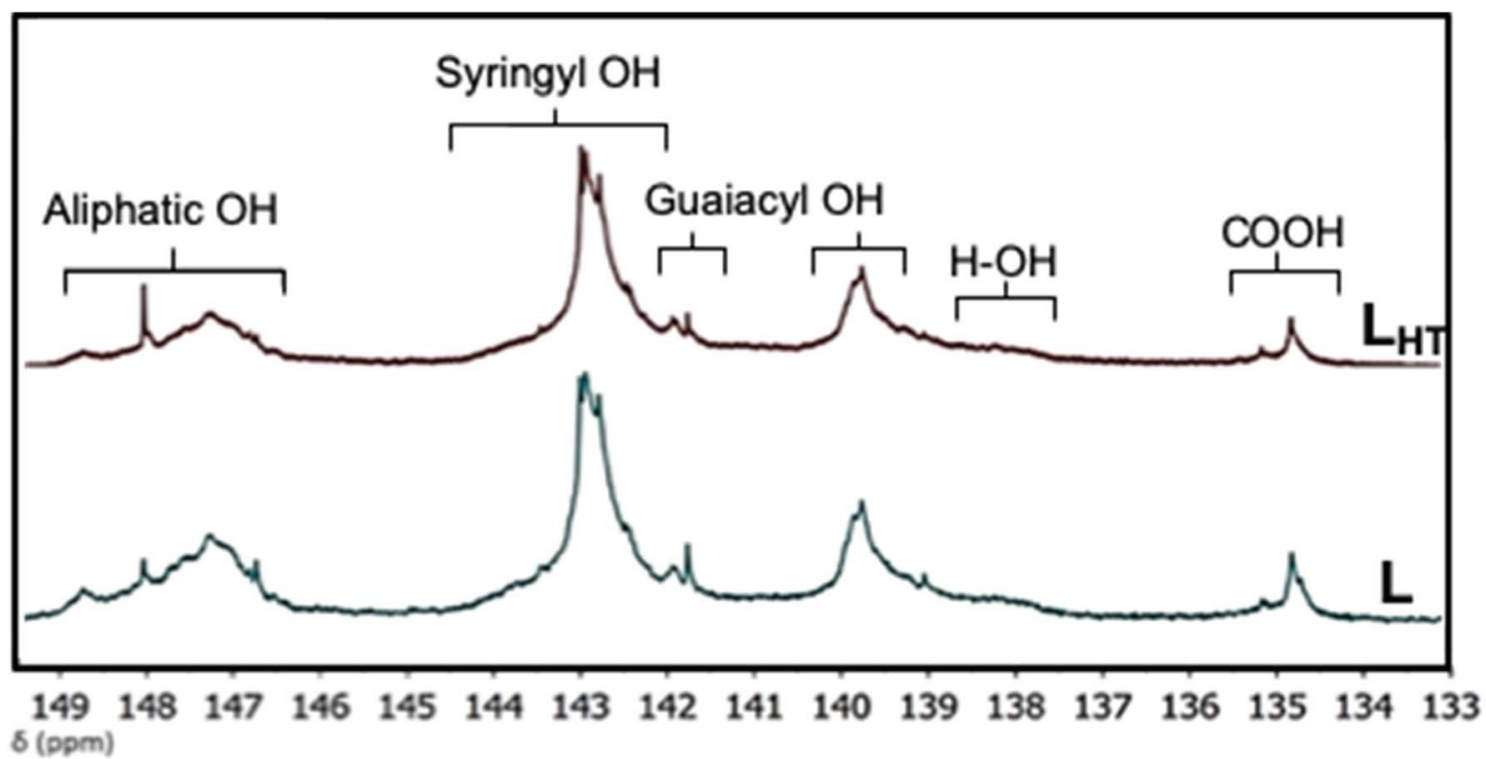

Fig. 1 Functional groups identified by quantitative ${ }^{31} \mathrm{P}$ NMR measurements after phosphitylation of lignins $L$ and $L_{H T}$.

condensation reactions that occurred during thermal treatment. Evidences of the reactions are found in features detected by ${ }^{31} \mathrm{P}$ NMR and $2 \mathrm{D}$ HSQC NMR. Thermal behaviors analysis by DSC agrees with these findings as glass transition temperature of lignin increased from $86^{\circ} \mathrm{C}$ to $97^{\circ} \mathrm{C}$ after thermal treatment (ESI Fig. S2\$). The degree of crosslinking was mild; otherwise, pronounced crosslinking would have enlarged the macromolecules to a higher range. For example, $\mathrm{L}_{\mathrm{HT}}$ would have had a higher molecular weight and reduced viscosity. The fact that $\mathrm{L}_{\mathrm{HT}}$ still flows at $\sim 165^{\circ} \mathrm{C}$ is an evidence of mild crosslinking. This also suggests that oxidation was avoided in vacuum. A treatment duration of 60 minutes should have been enough to advance the condensation reactions when conducted in an oxidative atmosphere. ${ }^{28}$

Thermal treatment improved thermal stability of the lignin through removal of volatiles, dehydration, crosslinking in aromatic structures and increasing the degree of condensation. ${ }^{25}$ As-received lignin started to degrade at $185^{\circ} \mathrm{C}$. Thermal treatment shifted the onset of degradation to higher temperatures to accommodate melt mixing with PET at $240{ }^{\circ} \mathrm{C}$. TGA thermograms of $\mathrm{L}$ and $\mathrm{L}_{\mathrm{HT}}$ are shown in Fig. S3 (ESI‡). Weight reduction temperatures recorded at $5 \%$ weight loss was $247^{\circ} \mathrm{C}$ for $\mathrm{L}$ compared to $265{ }^{\circ} \mathrm{C}$ for $\mathrm{L}_{\mathrm{HT}}$. The derivative weight thermogram of as-received lignin has a shoulder from $143{ }^{\circ} \mathrm{C}$ to
$258{ }^{\circ} \mathrm{C}$ that disappeared after thermal treatment by removing low molecular weight volatiles and cleaving thermally liable ether bonds. Overall, thermal treatment under vacuum only changed lignin's structure slightly to improve its thermal stability. This avoids significant oxidative degradation reactions that are detrimental to keeping the lignin malleable. In addition, the soak time of 60 minutes was sufficient to generate lignin that is thermally stable and malleable for blending with engineered polymer matrices.

\section{Thermal and morphological properties of the compositions}

Thermal transition temperatures, calorimetric values, and degree of crystallinity computed from cooling and second heating of DSC thermograms are shown in ESI (Table S3\%). The results suggest that addition of TOFA plasticizer reduces the melting temperature of the neat PET. The melting temperature of PET shifted from $247{ }^{\circ} \mathrm{C}$ to $239{ }^{\circ} \mathrm{C}$ in presence of $10 \mathrm{wt} \%$ TOFA. Plasticizers are small molecular weight materials that are added to help soften the rigid amorphous phase of polymer. It enhances segmental mobility by depressing the glass transition temperature $\left(T_{\mathrm{g}}\right)$ of the amorphous phase of the host polymers. The effect of the plasticizer on recrystallization during cooling is observed as the recrystallization temperature shifts from $208^{\circ} \mathrm{C}$ to $202{ }^{\circ} \mathrm{C}$.

Table 1 Functional groups $\left(\mathrm{mmol} \mathrm{g}^{-1}\right)$ of the $L$ lignin and thermally treated lignin $\left(L_{H T}\right)$ as determined by the quantitative ${ }^{31} \mathrm{P} N M R$ method

\begin{tabular}{|c|c|c|c|c|c|c|c|}
\hline \multirow[b]{2}{*}{ Samples } & \multirow[b]{2}{*}{$\begin{array}{l}\text { Aliphatic OH } \\
\delta 150-145 \\
\text { ppm }\end{array}$} & \multirow[b]{2}{*}{$\begin{array}{l}\text { Syringyl OH } \delta \\
144.5-142.25 \\
\text { ppm }\end{array}$} & \multicolumn{2}{|l|}{ Guaiacyl OH } & \multirow[b]{2}{*}{$\begin{array}{l}p \text {-Hydroxyphenyl } \\
\text { OH } \delta 138.5-136.5 \\
\text { ppm }\end{array}$} & \multirow[b]{2}{*}{$\begin{array}{l}\text { Total phenolic } \\
\text { OH } \delta 145-136.5 \\
\text { ppm }\end{array}$} & \multirow{2}{*}{$\begin{array}{l}\text { Carboxylic } \\
\text { group } \\
\delta 136-133.5 \\
\text { ppm }\end{array}$} \\
\hline & & & $\begin{array}{l}\mathrm{C}^{a} \delta 142.25-141 \\
\mathrm{ppm}\end{array}$ & $\begin{array}{l}\mathrm{NC}^{b} \delta 141-138.5 \\
\mathrm{ppm}\end{array}$ & & & \\
\hline L & 2.01 & 2.85 & 0.80 & 1.79 & 0.42 & 5.86 & 0.45 \\
\hline $\mathrm{L}_{\mathrm{HT}}$ & 1.63 & 3.08 & 0.96 & 2.04 & 0.56 & 6.64 & 0.46 \\
\hline
\end{tabular}

${ }^{a}$ Condensed. ${ }^{b}$ Non-condensed. Chemical shifts $(\delta)$ were ascribed as per Balakshin and Capanema $(2015) .{ }^{20}$ 

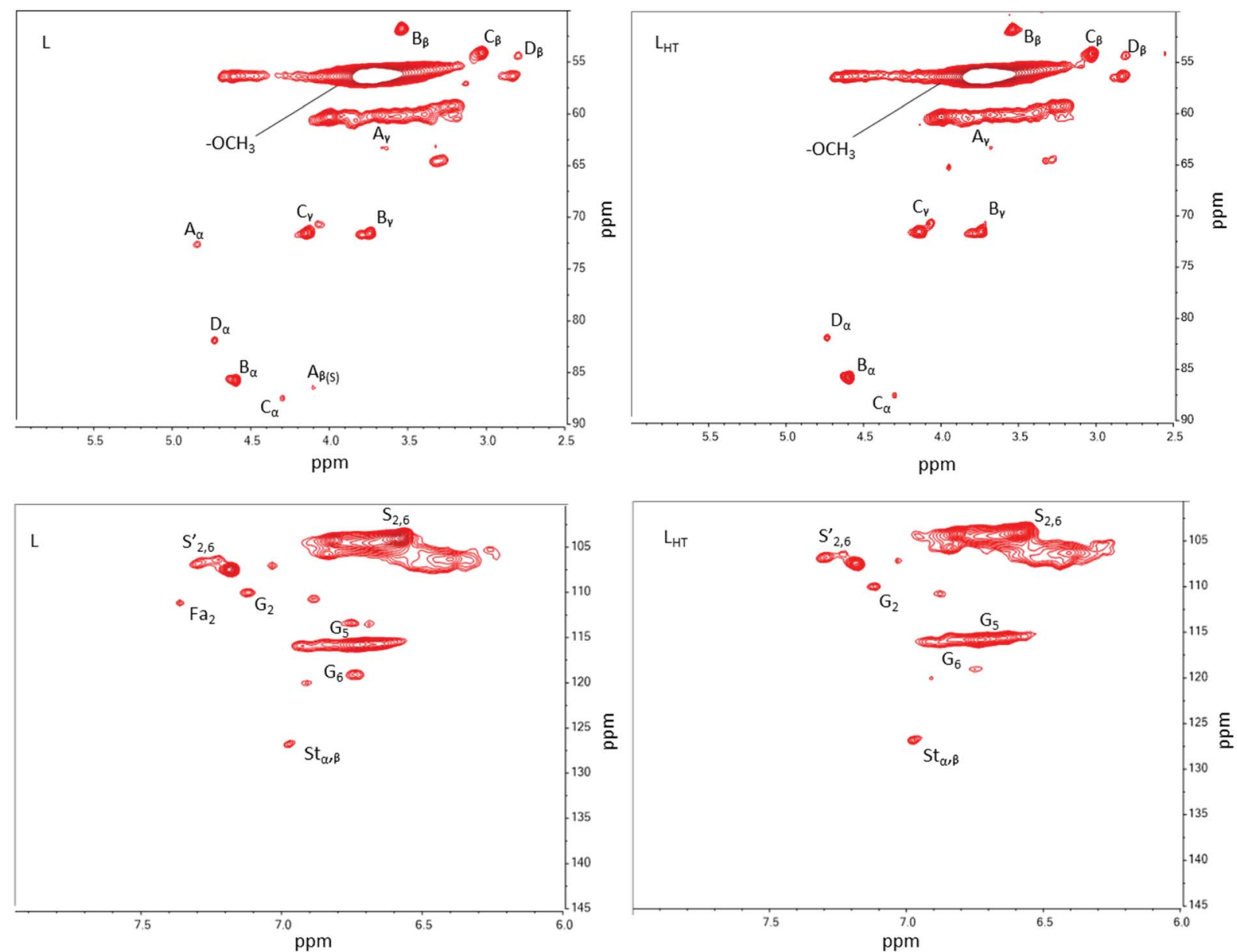

Fig. 2 Two-dimensional heteronuclear single quantum coherence (2D-HSQC) NMR spectra of both $L$ and $L_{H T}$ lignins. The top two images are the aliphatic oxygenated side chain region $\left(\delta_{\mathrm{C}} / \delta_{\mathrm{H}} 50-90 / 2.5-6\right)$ and the bottom two images represent the aromatic/unsaturated region $\left(\delta_{\mathrm{C}} / \delta_{\mathrm{H}}\right.$ 90-150/6-8).

Addition of lignins ( $\mathrm{L}$ and $\mathrm{L}_{\mathrm{HT}}$ ) in all compositions further reduces the melting temperatures and decreases the heat of fusion. This is evidence for reduction in crystallite sizes in PET with incorporation of lignin in the blends. Also, the difference between the behavior of $\mathrm{L}$ series alloys compared to $\mathrm{L}_{\mathrm{HT}}$ series alloys suggests variance in the degree of interactions between the lignins and PET. In theory, the addition of oligomeric lignin increases the free volume in the PET matrix which leads to the plasticization effect. Additionally, lignin addition shifts the recrystallization temperature $\left(T_{\text {rec }}\right)$ of PET to lower temperatures. Shifting of $T_{\text {rec }}$ and $\Delta H_{\text {rec }}$ suggests that lignin is decelerating the recrystallization and crystal growth during cooling. Conclusions from these results show that interactions exist between both lignins and PET. These interactions could be the hydrogen bonding and $\pi$ electron interactions. The degree of crystallinity $\left(\chi_{c}\right)$ was computed using eqn S1 (ESI) and heat of fusion. Presence of plasticizer lowers the crystallinity in PET matrix and presence of lignin further lowers the degree of crystallinity. Lignin loaded (10-30 wt\%) $\mathrm{PET}_{\mathrm{PL}}$ matrix exhibits $17-26 \%$ crystallinity.

Microscopic analysis of cryo-fractured surfaces of the blends (Fig. 3) shows that the morphologies depend on the nature of lignin at $30 \mathrm{wt} \%$ lignin contents in the blends. The samples were etched in $1 \mathrm{M}$ solution of $\mathrm{NaOH}$ to dissolve lignin from the cryo-fractured surface before SEM imaging. In Fig. 3a, the blend of PET and as-received lignin (L) shows lignin as less concentrated but larger droplets in the PET matrix. Lignin droplet sizes vary from 1 to 2 micrometers. However, the thermally treated lignin-derived PET blend shows formation of homogenously dispersed cavities after removal of lignin macromolecules $(0.2$ to 2 micrometer). Controlling lignin-lignin intermolecular interaction through thermal treatment by decreasing aliphatic hydroxyl helps avoid coalescence of the lignin phase during mixing in the engineered polyester matrix. It has been reported that controlling microstructure and dispersion of lignin in thermoplastic blends is important for improved performance. ${ }^{29}$

\section{Interfacial interactions-performance relationships}

Mechanical properties. Blending of lignin in thermoplastics often reduces tensile strength. This is primarily because the lignin forms large domains in thermoplastic matrices causing defect centers. However, lignin was reported to impart rigidity and stiffness in some systems. ${ }^{23}$ Improving overall performance 
(a)

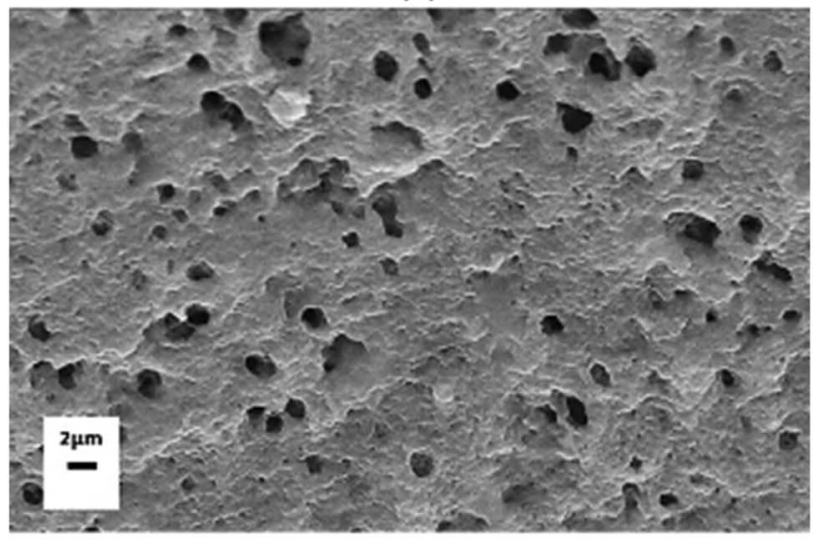

(b)

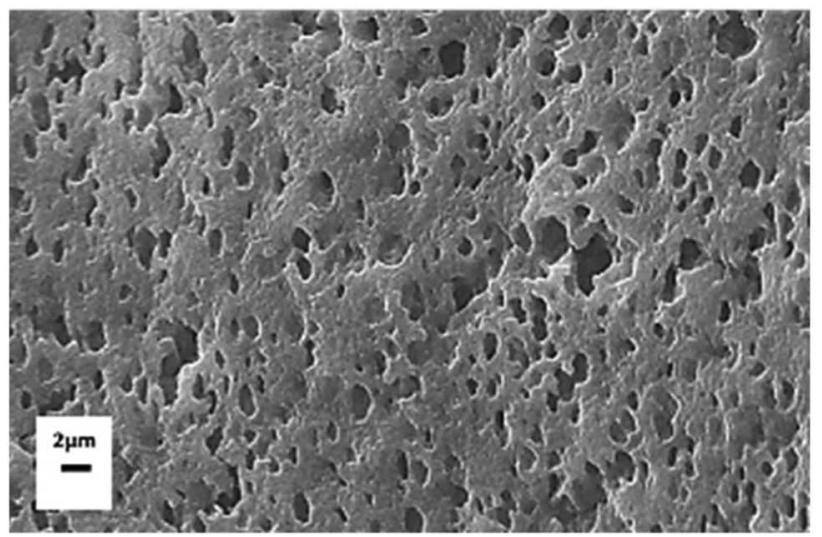

Fig. 3 Scanning electron micrographs of cryo-fractured and $\mathrm{NaOH}$ etched surfaces of $P E T_{P L} / 30 L$ (a) and $P E T_{P L} / 30 L_{H T}(b)$ blends.

of the blends relies on the level of interactions between the lignin and the host polymer molecules. Fig. 4a illustrates the relationship between the tensile strength presented as a ratio of tensile strength of the lignin-derived composites over the tensile strength of the matrix, in this case plasticized PET, as a function of weight fraction of lignin in the blends. The $\left(\sigma_{\mathrm{c}} / \sigma_{\mathrm{m}}\right)$ increases at low lignin loadings then diminishes with increasing lignin amount. Obviously, weak interactions between the PET and lignin generate large lignin domains in the blends (Fig. 3a) that affect performance of the blends negatively. Also, there is a possibility of thermal degradation of lignin during mixing at $240{ }^{\circ} \mathrm{C}$ leading to inferior performance. In this study, we find that the thermal pre-treatment improves lignin stability and helps to improve lignin dispersion in the PET matrix and, thus, the mechanical properties. Although thermal treatment increases the molar mass of $\mathrm{L}_{\mathrm{HT}}$, mechanical shear during blending helps to break the aggregates of lignin macromolecules into finer droplets compared to the system consisting of original lignin, L. Low lignin-loaded compositions show slightly improved performance of the plasticized PET matrix when combined with $\mathrm{L}_{\mathrm{HT}}$ as compared to its control counterparts.

The compositional dependence of the mechanical properties limits our ability to draw a definitive conclusion on the interactions in each blend. We observe, however, that better interactions exist between the $\mathrm{L}_{\mathrm{HT}}$ and the PET compared to $\mathrm{L}$ blends. Nevertheless, the results of L series imply that some level of interactions is also occurring between L and PET, possibly competing hydrogen bonding between the lignin $\mathrm{OH}$ and PET end groups (ester and ethylene groups) and $\pi-\pi$ interaction between aromatic groups of lignin and PET. Overall, the representative tensile stress-strain curves of the PET and its high lignin containing blends formulated at $260{ }^{\circ} \mathrm{C}$ and $240{ }^{\circ} \mathrm{C}$ (respective Fig. $4 \mathrm{c}$ and d) are in agreement that a combination of plasticization effects induced by the addition of TOFA and thermal treatment of lignin helped to enhanced performance of the blends. It may also be noted that the presence of lignin in the TOFA modified PET matrix enhances ductility of the product significantly. Recycled PET-based lignin-derivatives with $30 \%$ or higher elongation at failure is significant compared to the neat waste PET and plasticized waste PET that shows $<5 \%$ and $\sim 20 \%$ elongation, respectively.

Fig. $4 \mathrm{~b}$ shows natural logarithm of reduced tensile strength as a function of volume fraction of lignin. The reduced tensile strength is described by eqn (1). ${ }^{30}$ The plot is used for quantitative estimation of interaction using the composition dependence of strength model. The model relates the interfacial interactions, structure and the mechanical properties of the blends. It is expressed to reflect the effect of volume fraction $(\varphi)$ of the dispersed component, and the load bearing capacity of the dispersed lignin constituent $(B)$, which is dependent on interfacial adhesion..$^{31,32}$

$$
\sigma_{\text {Tred }}=\sigma_{T} \frac{1+2.5 \phi}{1-\phi}=\sigma_{T 0} \exp (B \phi)
$$

here, $\sigma_{\text {Tred }}$ is the reduced tensile strength of the blend, $\sigma_{\mathrm{T}}$ and $\sigma_{\mathrm{T} 0}$ are the tensile strength of the blends and the matrix, respectively.

The results are summarized in Table 2. It reveals that parameter $B$, which is the slope of the linear correlation applied to the data, increased from 1.82 to 2.24 when the thermally treated lignin $\mathrm{L}_{\mathrm{HT}}$ was used instead of $\mathrm{L}$ highlighting divergent interfacial adhesion. Thermal treatment was beneficial to improve thermal stability, control lignin-lignin intermolecular interactions and to control lignin-PET interaction likely through a combination of hydrogen bonding and $\pi$ electron interactions that is clearly different in the composites based on as-received lignin (L). Calculated tensile stress of the matrix $\left(\sigma_{\mathrm{T} 0}\right)$ for both cases ( $\mathrm{L}$ and $\mathrm{L}_{\mathrm{HT}}$ series) agrees well with the measured value.

Dynamic mechanical analysis. Loss tangent $(\tan \delta)$ peaks for PET and its lignin-based alloys at $10 \mathrm{~Hz}$ frequency are shown in Fig. 5. Neat PET shows a narrow $\tan \delta$ peak representative of its glass transition temperature $\left(T_{\mathrm{g}}\right)$ at $101^{\circ} \mathrm{C}$. This shift is likely attributed to the presence of TOFA at $10 \mathrm{wt} \%$ of PET in each blend. The $\tan \delta$ peaks became broader in the presence of lignin in PET matrix and increasing lignin content increased the $T_{\mathrm{g}}$. When lignin $L$ is used, moderate interactions with PET matrix are expected. The $T_{\mathrm{g}}$ is $86{ }^{\circ} \mathrm{C}$ for a $10 \mathrm{wt} \%$ lignin loading in plasticized PET; use of $\mathrm{L}_{\mathrm{HT}}$ makes better dispersion and interactions with PET matrix and thus, a slight increase in $T_{\mathrm{g}}$ is 
(a)

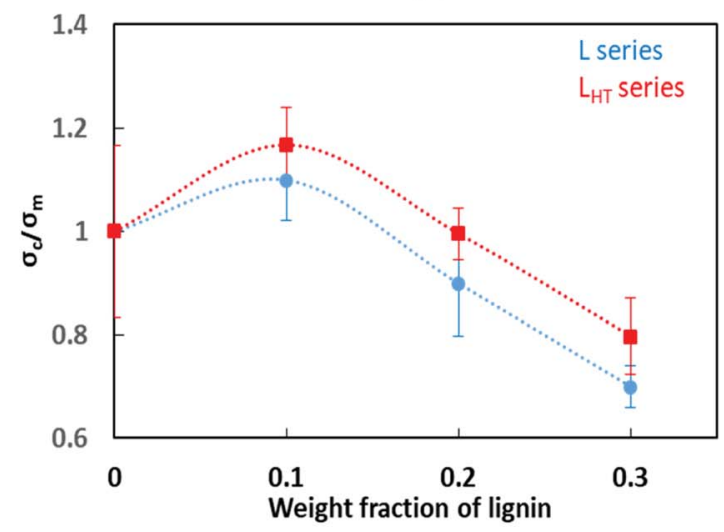

(c)

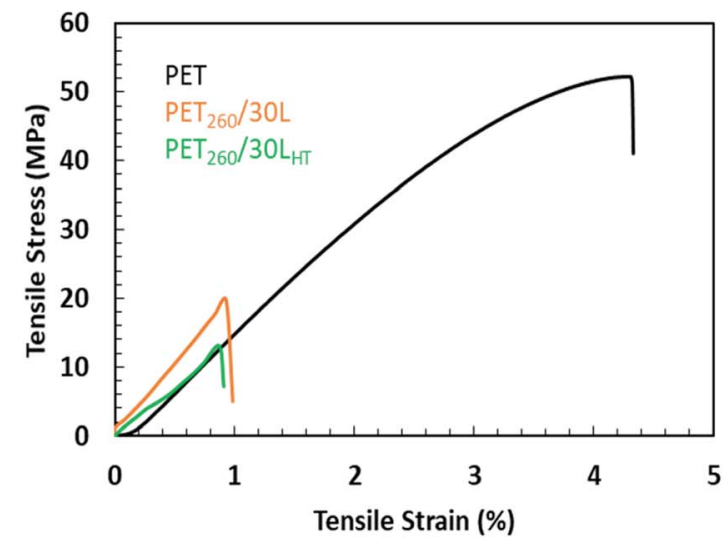

(b)

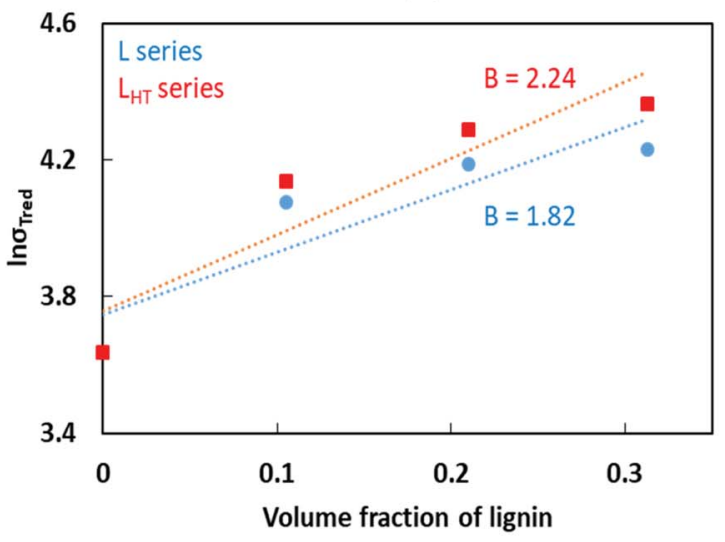

(d)

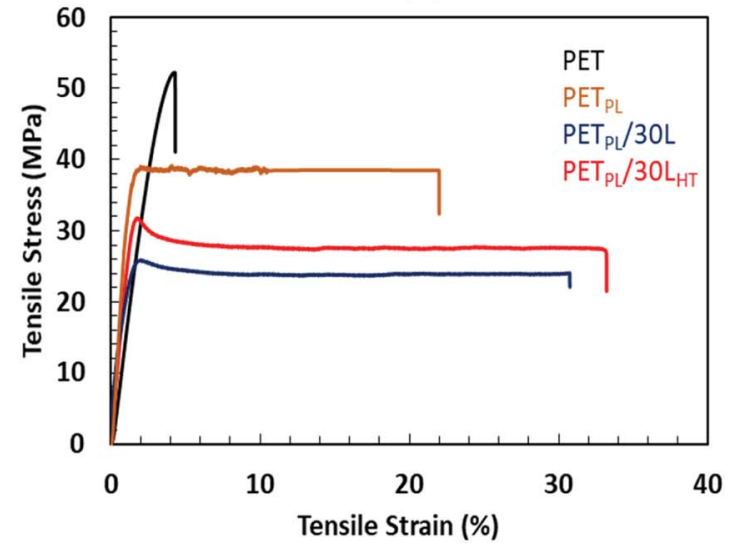

Fig. 4 Ratios of tensile strength of lignin-loaded matrices over those of neat PET at different lignin weight fraction (a), the natural logarithm of reduced tensile strength as a function of volume fraction of lignin (b), Tensile stress-strain curves of (c) neat PET and its lignin-derived blends amalgamated at $260^{\circ} \mathrm{C}$ and (d) plasticized PET and its lignin-derived blends amalgamated at $240{ }^{\circ} \mathrm{C}$ showing enhanced mechanical properties of the blends due to plasticization effects of tall oil fatty acid and thermal treatment of lignin.

observed $\left(89^{\circ} \mathrm{C}\right)$. Similar observations were made in the case of higher lignin loading $(30 \mathrm{wt} \%)$ in blends.

The loss tangent data represents the energy dissipated by the materials under cyclic load. Application of the Arrhenius equation to the loss factor $(\tan \delta$ ) peak temperature as a function of frequency data provides quantitative evaluation for the relaxation behavior of PET phase in the blends. In this instance, the Arrhenius equation can be expressed in the following form:

$$
\log f=\frac{-E_{\mathrm{a}}}{(2.303 R T)}+\log K
$$

Table 2 Quantitative estimation of interactions computed from mechanical properties of the blends

\begin{tabular}{llllll}
\hline & & \multicolumn{2}{l}{$\sigma_{\mathrm{T} 0}(\mathrm{MPa})$} & & \\
\cline { 3 - 4 } Lignin & Treatment & Measured & Calculated $^{b}$ & $B$ & $R^{2}$ \\
\hline $\mathrm{L}$ & As-received & $38.12(6.31)^{a}$ & 42.09 & 1.82 & 0.87 \\
$\mathrm{~L}_{\mathrm{HT}}$ & Heat treated & & 42.94 & 2.24 & 0.89
\end{tabular}

${ }^{a}$ standard deviation is shown in parenthesis. ${ }^{b}$ Computed from the $y$ intercept of $\ln \sigma_{\text {Tred }} v s$. volume fraction of lignin plots. here $T$ is the absolute temperature at which the loss maximum is observed at frequency $f, R$ is the gas constant, $K$ is an arbitrary constant, and $E_{\mathrm{a}}$ is activation energy associated with glassy to rubber transition or relaxation. Table 3 shows computed $E_{\text {a }}$ data for neat PET (404 $\mathrm{kJ} \mathrm{mol}^{-1}$ ). Addition of TOFA reduced the activation energy in PET. However, the thermally treated lignin alloys have higher $E_{\mathrm{a}}$ compared to the as-received lignin compositions in TOFA plasticized PET; although, the increase in $E_{\mathrm{a}}$ becomes marginal at high $\mathrm{L}_{\mathrm{HT}}$ content in the blend. Two phenomena are occurring simultaneously. First, the plasticizer is helping to depress $T_{\mathrm{g}}$ while rigid lignin hinders segmental motion of PET. Treated lignin $\mathrm{L}_{\mathrm{HT}}$ has a higher degree of interaction with PET matrix and thus restrains the flexibility of the PET phase. At high $\mathrm{L}_{\mathrm{HT}}$ loading, however, the advantageous effect of improved dispersion on relaxation of PET matrix diminishes.

\section{Process engineering and degradation parameters of partially renewable blends}

PET is a semi-crystalline polymer. Its normal processing temperatures is between $270{ }^{\circ} \mathrm{C}$ to $280{ }^{\circ} \mathrm{C}$. Blending of lignin 


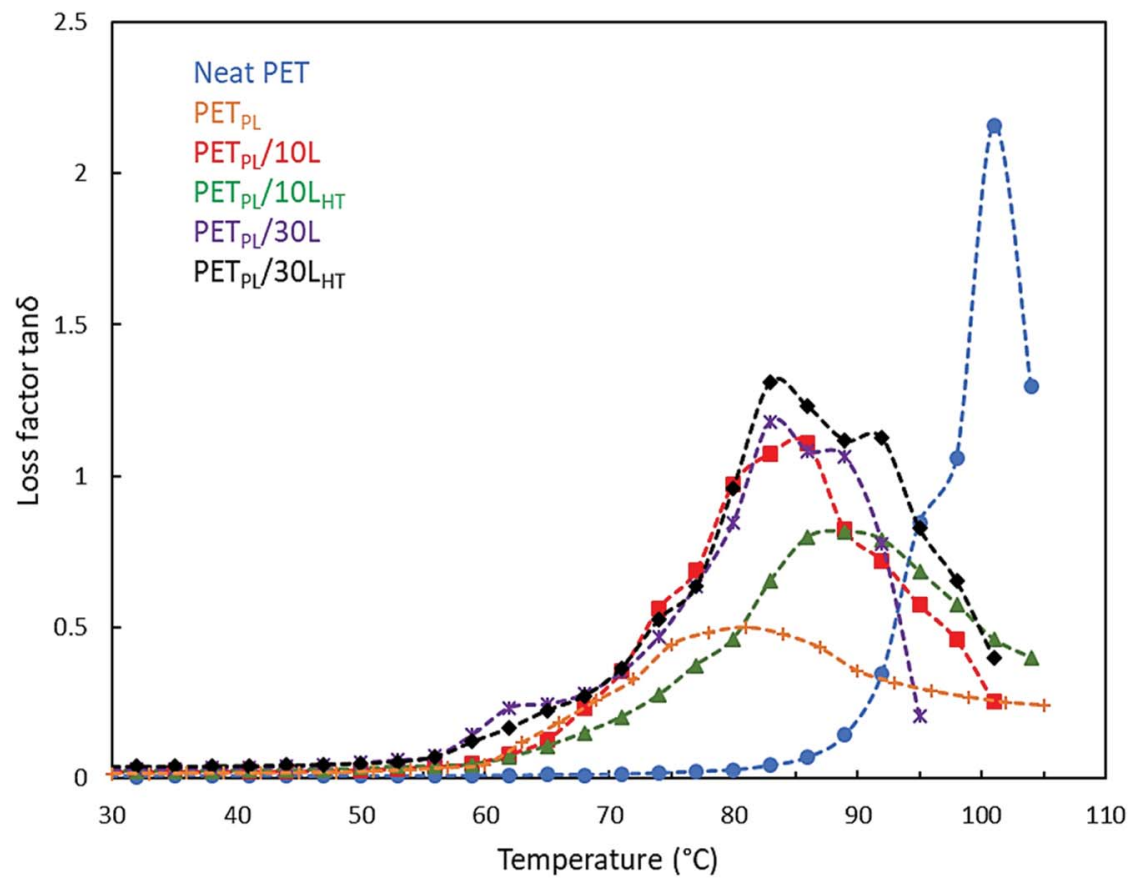

Fig. 5 Loss tangent peak of PET, plasticized PET and its derived blends with L and LHT at in different compositions at $10 \mathrm{~Hz}$ frequency.

with PET requires manipulating the PET thermal behavior to prevent degradation of lignin. Our approach to address this involves use of a renewable plasticizer to soften PET matrix. In practice, low molecular weight plasticizers are often added to increase the flexibility at room temperature and to improve processing. All blends studied in this report were mixed at $240{ }^{\circ} \mathrm{C}$, a processing temperature of PET that was enabled by the addition of plasticizer.

In thermoplastic matrix-lignin systems, compatibility and dispersion of lignin are desired for enhanced mechanical properties. ${ }^{33}$ Often, partial or full miscibility help improve the properties of the blends. Our results show some level of affinity between the L lignin and PET. However, such interactions are improved when $\mathrm{L}_{\mathrm{HT}}$ is used. Miscibility could have been increased by raising the melt-mixing temperature, but that approach would degrade the lignin, causing charring and subsequent phase separation during shear mixing. Viscous heating is another cause of lignin degradation during meltmixing. Thus, rheological behaviors of the components and the blends are important. Ultimately, the process depends on the molecular structures of the components. Therefore, differences in lignin molecular structure are expected to affect rheological behaviors of the resulting polymer blends.

Influence of lignin molar structure on flow characteristics of the PET blends is illustrated in Fig. 6. The angular frequency $(\omega)$ dependence of the complex viscosity $\left(\eta^{*}\right)$ and the storage modulus $\left(G^{\prime}\right)$ were used to study flow characteristics of neat PET, its plasticized blend at $10 \mathrm{wt} \%$ plasticizer amount $\left(\mathrm{PET}_{\mathrm{PL}}\right)$, and its lignin derived blends at high-lignin-loading (30 wt\%) at reference temperatures of $240{ }^{\circ} \mathrm{C}$ and $250{ }^{\circ} \mathrm{C}$. Plasticization outcome is clear as the viscosity decreased at both temperatures with increasing frequency. The materials stiffness at $240{ }^{\circ} \mathrm{C}$ is higher compared to its stiffness at $250{ }^{\circ} \mathrm{C}$ (Fig. 6c and d). Addition of lignin further decreases the viscosity and the storage modulus at both reference temperatures, suggesting a role of viscous oligomeric lignin on plasticization of the PET. Interestingly, the blend with thermally treated lignin ( $\mathrm{PET}_{\mathrm{PL}} /$ $30 \mathrm{~L}_{\mathrm{HT}}$ ) has higher viscosity and storage modulus than the asreceived lignin blend $\left(\mathrm{PET}_{\mathrm{PL}} / 30 \mathrm{~L}\right)$. As discussed earlier, this is due to the homogenous dispersion of $\mathrm{L}_{\mathrm{HT}}$ in PET (as shown by microscopy), and possible enhanced interfacial interactions through combination of hydrogen bonding and $\pi-\pi$ interaction

Table 3 Temperatures corresponding to the loss tangent peak $\left(T_{\mathrm{g}}\right)$ at different frequencies from the dynamic mechanical analysis, and the activation energy $\left(E_{\mathrm{a}}\right)$ associated with thermal relaxation at $T_{\mathrm{g}}$

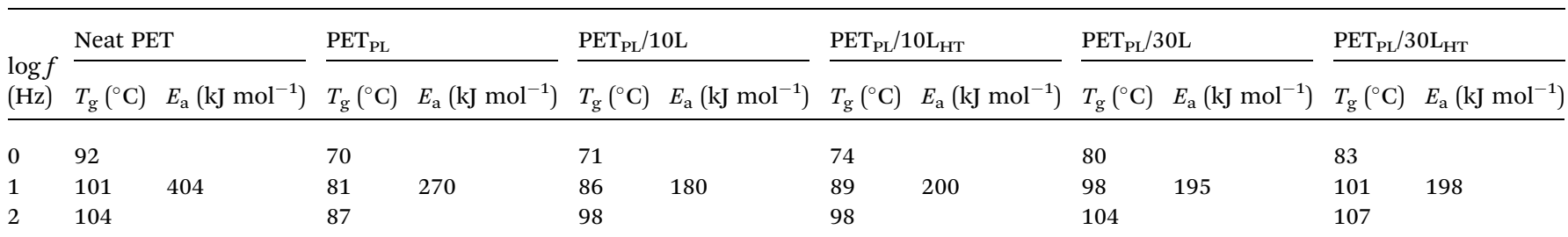


(a)

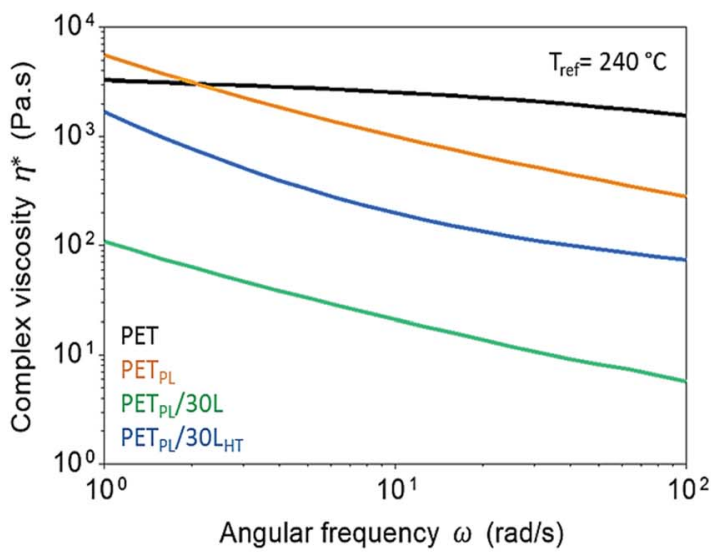

(c)

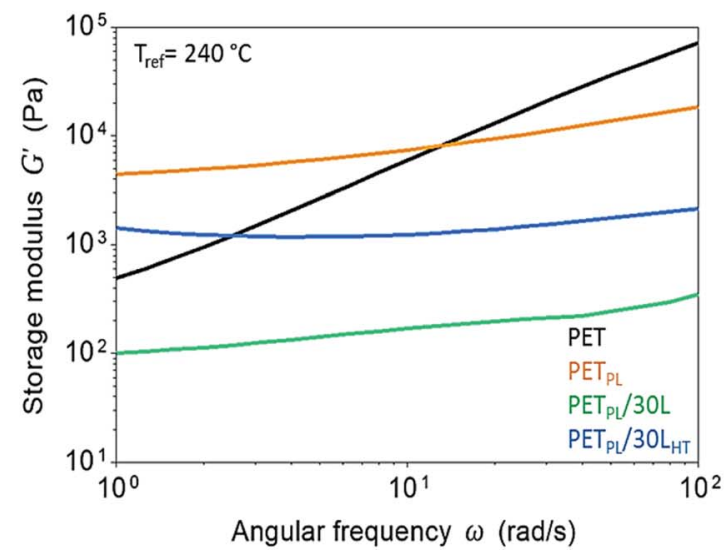

(b)

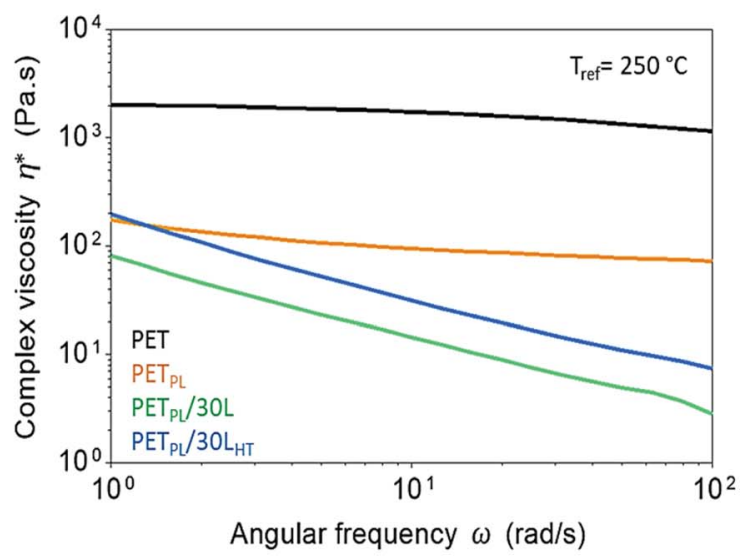

(d)

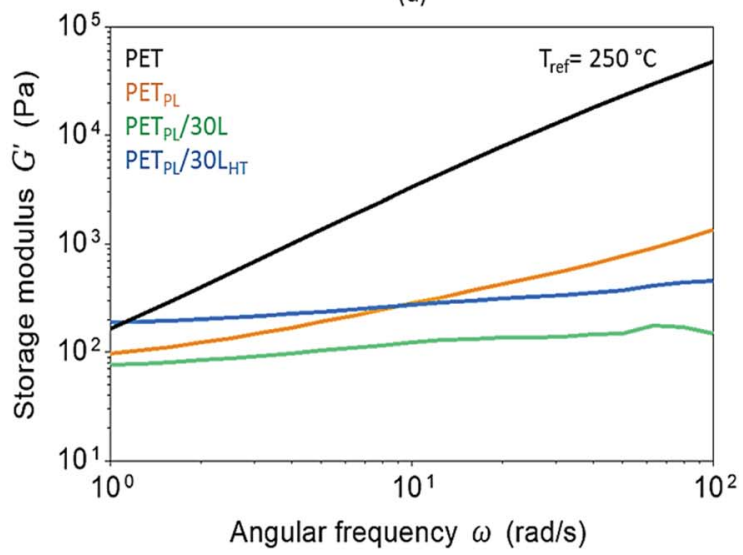

Fig. 6 Frequency-dependent complex viscosity $\left(\eta^{*}\right)$ at $T_{\text {ref }}=240{ }^{\circ} \mathrm{C}(\mathrm{a})$ and $250{ }^{\circ} \mathrm{C}(\mathrm{b})$ and frequency-dependent storage modulus $\left(G^{\prime}\right)$ at $T_{\text {ref }}=$ $240{ }^{\circ} \mathrm{C}$ (c) and $250{ }^{\circ} \mathrm{C}$ (d) of recycled PET, its plasticized resin (PET $\mathrm{PL}$ ), and its lignin-derived blends (PET $\mathrm{PL} / 30 \mathrm{~L}$ and $\mathrm{PET} P \mathrm{PL} / 30 \mathrm{~L}_{\mathrm{HT}}$ ).

of lignin with PET chains and restrained chain disentanglement along with retardation of segmental relaxation (in accordance to DMA data around the glass transition temperature $T_{\mathrm{g}}$ of the blends).

Thermogravimetric analysis was used to evaluate thermal degradation behavior of the blends in oxidative atmosphere. Mass loss data collected at $20^{\circ} \mathrm{C} \mathrm{min}^{-1}$ scanning rate are shown in Fig. S4 in ESI. $\$$ The results are summarized in Table 4. Addition of lignin reduces the temperature corresponding to $5 \%$ mass loss $\left(T_{\mathrm{i}}\right)$ and the onset temperature $\left(T_{\mathrm{d}}\right)$ but increases the derivative weight peak temperature. Addition of lignin improves net degradation of the blends and confirms the effect

Table 4 Thermal degradation parameters of neat PET, $P E T_{P L} / 30 L$ and $\mathrm{PET}_{\mathrm{PL}} / 30 \mathrm{~L}_{\mathrm{HT}}$

\begin{tabular}{llll}
\hline & PET & PET $_{\mathrm{PL}} / 30 \mathrm{~L}$ & PET $_{\mathrm{PL}} / 30 \mathrm{~L}_{\mathrm{HT}}$ \\
\hline 5\% weight loss temp. $T_{\mathrm{i}}\left({ }^{\circ} \mathrm{C}\right)$ & 391 & 290 & 303 \\
Onset temperature $T_{\mathrm{d}}\left({ }^{\circ} \mathrm{C}\right)$ & 400 & 388 & 390 \\
DTG peak temperature $\left({ }^{\circ} \mathrm{C}\right)$ & 436 & 438 & 440 \\
Mass at $300{ }^{\circ} \mathrm{C}(\%)$ & 99.9 & 93.9 & 95.3 \\
Mass at $500{ }^{\circ} \mathrm{C}(\%)$ & 14.3 & 27.1 & 27.6
\end{tabular}

of thermal treatment of lignin on the thermal stability of the blends. $\mathrm{L}_{\mathrm{HT}}$ blend is marginally more stable at higher temperatures than the $\mathrm{L}$ blend. Additionally, mass at $500{ }^{\circ} \mathrm{C}$ increased with the addition of lignin showing the protective effect of lignin at higher temperatures.

\section{Conclusion}

We have successfully demonstrated that lignin dispersion and interfacial interaction can be controlled in recycled PET/lignin alloys through thermal pre-treatment of lignin. The addition of renewable plasticizer at $10 \mathrm{wt} \%$ relative to PET helped to soften PET below its normal processing temperature to avoid further degradation of lignin during mixing. Thermal treatment of lignin decreases the aliphatic hydroxyl group, minimizes lignin-lignin intermolecular interactions and improves lignin thermal stability. Relative tensile failure stress of lignin-PET alloys with respect to that of the PET matrix $\left(\sigma_{\mathrm{c}} / \sigma_{\mathrm{m}}\right)$ improves by $15 \%$, in the presence of thermally pretreated lignin at a composition of $30 \mathrm{wt} \%$. Small amount of lignin (10\%) in the PET matrix shows a reinforcing effect. Computed interfacial interaction of the dispersed lignin with the PET matrix improves significantly when thermally pretreated lignin is used. 
This clearly shows that combined interactions (hydrogen bonding and $\pi$ electron interactions) are enhanced after heat treatment of lignin. Dynamic mechanical analysis and rheology study confirm balanced interactions between the PET and heattreated lignin as oligomeric lignin is known to enhance chain disentanglement (shear thinning) and restrain segmental motion resulting in increased $T_{\mathrm{g}}$. Our formulations use lignin, a low-cost renewable resource, post-industrial PET waste destined for landfills, and renewable plasticizer TOFA, a lowpriced by-product from pulping industries to develop a renewable material with well dispersed lignin domain and good mechanical performance. This work highlights development of renewable thermoplastics based on lignin and sustainable industrial waste PET, offering a path for high-volume utilization of lignin in a value-added form.

\section{Conflicts of interest}

There are no conflicts to declare.

\section{Acknowledgements}

This project is supported by the Sun Grant Initiative and by Agriculture and Food Research Initiative Competitive Grant no. 2014-38502-22598 from the USDA National Institute of Food and Agriculture and by the USDA National Institute of Food and Agriculture, Hatch project 1012359. N. A. N. acknowledges support from the U. S. Department of Energy (DOE), Office of Energy Efficiency and Renewable Energy, BioEnergy Technologies Office Program for the rheological analysis of the materials. A. K. N. acknowledges support from the Laboratory Directed Research and Development Program of Oak Ridge National Laboratory, managed by UT-Battelle, LLC, for the US Department of Energy.

\section{References}

1 S. Yearley, Ambiente Sociedade, 2005, 8, 11-26.

2 P. Koltun, Prog. Nat. Sci.: Mater. Int., 2010, 20, 16-29.

3 M. A. Mohsin, T. Abdulrehman and Y. Haik, Int. J. Chem. Eng., 2017, 2017, 10.

4 T. Ochi, S. Okubo and K. Fukui, Cem. Concr. Compos., 2007, 29, 448-455.

5 Z. Dehghan and A. Modarres, Constr. Build. Mater., 2017, 139, 384-393.

6 A. Pawlak, J. Morawiec, F. Pazzagli, M. Pracella and A. Galeski, J. Appl. Polym. Sci., 2002, 86, 1473-1485.

7 G. Burillo, P. Herrera-Franco, M. Vazquez and E. Adem, Radiat. Phys. Chem., 2002, 63, 241-244.

8 S. K. Taghavi, H. Shahrajabian and H. M. Hosseini, J. Elastomers Plast., 2018, 50, 13-35.

9 C. Fang, R. Yang, Z. Zhang, X. Zhou, W. Lei, Y. Cheng, W. Zhang and D. Wang, RSC Adv., 2018, 8, 8920-8928.
10 J. F. Kadla and S. Kubo, Composites, Part A, 2004, 35, 395400.

11 S. Kubo and J. F. Kadla, J. Polym. Environ., 2005, 13, 97-105.

12 M. Canetti and F. Bertini, Compos. Sci. Technol., 2007, 67, 3151-3157.

13 A. Chaudhari, J. D. Ekhe and S. Deo, Int. J. Polym. Anal. Charact., 2006, 11, 197-207.

14 H. Jeong, J. Park, S. Kim, J. Lee and J. W. Cho, Fibers Polym., 2012, 13, 1310-1318.

15 S. Kim, J. Park, J. Lee, H.-g. Roh, D. Jeong, S. Choi and S. Oh, Fibers Polym., 2015, 16, 744-751.

16 G. E. Agafitei, M. C. Pascu, G. Cazacu, A. Stoleriu, N. Popa, R. Hogea and C. Vasile, Angew. Makromol. Chem., 1999, 267, 44-51.

17 F. Monteil-Rivera and L. Paquet, Ind. Crops Prod., 2015, 65, 446-453.

18 A. V. Maldhure, A. R. Chaudhari and J. D. Ekhe, J. Therm. Anal. Calorim., 2011, 103, 625-632.

19 K. M. Akato, N. A. Nguyen, P. V. Bonnesen, D. P. Harper and A. K. Naskar, ACS Omega, 2018, 3, 10709-10715.

20 M. Balakshin and E. Capanema, J. Wood Chem. Technol., 2015, 35, 220-237.

21 A. Guerra, I. Filpponen, L. A. Lucia and D. S. Argyropoulos, J. Agric. Food Chem., 2006, 54, 9696-9705.

22 O. Hosseinaei, D. P. Harper, J. J. Bozell and T. G. Rials, ACS Sustainable Chem. Eng., 2016, 4, 5785-5798.

23 C. D. Tran, J. Chen, J. K. Keum and A. K. Naskar, Adv. Funct. Mater., 2016, 26, 2677-2685.

24 T. Bova, C. D. Tran, M. Y. Balakshin, J. Chen, E. A. Capanema and A. K. Naskar, Green Chem., 2016, 18, 5423-5437.

25 J.-Y. Kim, H. Hwang, S. Oh, Y.-S. Kim, U.-J. Kim and J. W. Choi, Int. J. Biol. Macromol., 2014, 66, 57-65.

26 S. Constant, H. L. J. Wienk, A. E. Frissen, P. d. Peinder, R. Boelens, D. S. van Es, R. J. H. Grisel, B. M. Weckhuysen, W. J. J. Huijgen, R. J. A. Gosselink and P. C. A. Bruijnincx, Green Chem., 2016, 18, 2651-2665.

27 Y. Zhang, J.-Q. Wu, H. Li, T.-Q. Yuan, Y.-Y. Wang and R.-C. Sun, ACS Sustainable Chem. Eng., 2017, 5, 7269-7277.

28 J. F. Kadla, S. Kubo, R. A. Venditti, R. D. Gilbert, A. L. Compere and W. Griffith, Carbon, 2002, 40, 2913-2920.

29 C. Pouteau, S. Baumberger, B. Cathala and P. Dole, Comptes Rendus Biol., 2004, 327, 935-943.

30 B. Turcsanyi, B. Pukanszky and F. Tudos, J. Mater. Sci. Lett., 1988, 7, 160-162.

31 E. Fekete, B. Pukánszky and Z. Peredy, Angew. Makromol. Chem., 1992, 199, 87-101.

32 G. Szabó, V. Romhányi, D. Kun, K. Renner and B. Pukánszky, ACS Sustainable Chem. Eng., 2017, 5, 410-419.

33 K. Akato, C. D. Tran, J. H. Chen and A. K. Naskar, ACS Sustainable Chem. Eng., 2015, 3, 3070-3076. 